\title{
Aerosol Optical Depth Trends over Different Regions of Nigeria: Thirteen Years Analysis
}

\author{
Moses E. Emetere ${ }^{1}$, M. L. Akinyemi ${ }^{1}$ \& O. Akin-Ojo ${ }^{2}$ \\ ${ }^{1}$ Physics Department, Covenant University, Nigeria \\ ${ }^{2}$ Physics Department, African University of Science and Technology, Nigeria \\ Correspondence: Moses E. Emetere, Physics Department, Covenant University, P.M.B. 1023, Ota-Ogun State, \\ Nigeria. Tel: 234-803-526-7598. E-mail: moses.emetere@covenantuniversity.edu.ng
}

Received: January 31, 2015

Accepted: April 18, $2015 \quad$ Online Published: August 30, 2015

doi:10.5539/mas.v9n9p267

URL: http://dx.doi.org/10.5539/mas.v9n9p267

\begin{abstract}
Recurrent challenges of the theoretical estimation of aerosol optical thickness (AOT) are traceable to bogus assumption in its mathematical model. The objective of this paper is to propound a model that could describe the aerosol distribution sizes per time. The physics of the salient properties of aerosol within the Stokes regime was discussed. The mathematical model was applied to six locations within $335 \times 230 \mathrm{Km} 2$ area of a selected portion of south-west, Nigeria. Though the climatic change is evident via thirteen years ground data set assimilation, the sensitivity of the proposed model was proven to increase by $0.1 \%$. The research affirmed the use of some parameters (e.g. minimum temperature, cloud cover, relative humidity and rainfall) to estimate aerosol optical thickness and by extension the aerosol distribution size over an area.
\end{abstract}

Keywords: aerosol optical thickness, forecast, minimum temperature, cloud cover, relative humidity, rainfall, model

\section{Introduction}

1) Aerosol optical thickness is a dimensionless parameter that indicates the attenuation of radiation as it passes through layers of the atmosphere- containing aerosols. Aerosols resides in distinct layers of the atmosphere i.e. stratospheric or Junge layer (contains volcanic sulfuric acid aerosols), tropospheric layer (composed primarily of dust, smoke or occasional industrial haze) and planetary boundary layer (composed primarily of sources and sinks of atmospheric aerosols). The effect AOT can be quantified by its magnitude. For example, there is crystal clear sky if the AOT is less than 0.1. Also, AOT of magnitude of 1 indicates very hazy sky of poor visibility. Models are propounded to maximize the functionality and accuracy of the measuring instruments (Zhang et al., 2008; Hollingsworth et al., 2008). Unfortunately, these model needs improvement in several areas e.g. adequate estimation of aerosol dispersion and deposition (Emetere et al., 2013; Emetere, 2013; Emetere, 2014), rates of new particle formation and their dependence on controlling variables e.g. growth and aging. Modeling AOT in the PBL is challenging because of the expansion and contraction of PBL sub-layers during day and night. For example, the PBL eliminates aerosol via a mechanism which operates either as wet deposition, dry deposition or chemical reactions. These processes can occur individually or simultaneously. Von Hoyningen-Huene et al., (2008) calculated aerosol optical thickness by using phase function and single scattering albedo. Wang et al., (2006) and Bockmann (2001) calculated AOT by using aerosol size distribution. This means that a higher AOT value indicates higher column of aerosol loading and lower visibility (Wang et al.,, 2003). Hoff et al., (2009) monitored the PBL activities via the aerosol size distribution; he concluded that it was inadequate to estimate AOT using fine particulate matter (PM2.5). The leading description of the aerosol optical thickness was given as

$$
\tau_{a}=C(\lambda)^{-\alpha}
$$

Here, $\alpha$ is the Angstrom parameter, $\tau \mathrm{a}$ is the aerosol optical depth, $\mathrm{C}$ is the concentration of aerosol and $\lambda$ is the wavelength. Eck et al., (1999) redefined the above equation as 


$$
\alpha=-\frac{d \operatorname{In}\left(\tau_{a}\right)}{\operatorname{dIn}(\lambda)}
$$

The application of this model showed inadequacy in near and middle infrared channel because of the presence of water vapour in the atmosphere (Tanre et al., 1988). The relative humidity (Fitzgerald,1989) and temperature (Bird,1984) will also be affected in the near and middle infrared channel. Here, we propose that the cloud cover would be affected. Since all these parameters are dependent on the wavelength during measurement, we assume that if the same wavelength could determine water vapour or rainfall, temperature, then the near and middle infrared channel could determine the relative humidity and cloud cover. For example, the minimum temperature is important to this study because it is measured at the lowest temperature layer called Ramdas layer. This parameter expresses the aerosol microphysical properties and transport. Another parameter is the cloud cover. This is the portion/fraction of the sky obscured by clouds which defines the interaction of thermal radiation effects on atmospheric aerosols. Relative humidity measures the amount of moisture in the air relative to the total amount of moisture the air can hold. Rainfall eliminates aerosol in the PBL.

In this paper, thirteen years ground data set assimilation was carried-out to observe the consistency of the data and the effect of climate change. This enables a comparative formulation of a model which is based on the peculiarity of the weather parameter. The uniqueness of the model was tested in six locations of the south-west Nigeria. The main objective is to propound a model that (that is climate change dependent) to give a rough estimate of aerosol distribution size over an area/location.

The research sites (shown in Figure 1) transverses the coastal region to the sub-Sahel region of Nigeria. The wind transport mechanism in this region is dynamic and can be described by the Reynolds' number which defines turbulent or laminar flow stress in the PBL. For example, during harmattan, the wind transports large quantities of dust particles from the Sahara Desert (from the north) to the south and aerosol from bush burning from the south to the north. During the non-harmattan, the West African Sub region is washed by the humid SW Monsoon winds from the Atlantic Ocean (see Figure 1) towards the north. In this paper, six locations were considered across the $335 \times 230 \mathrm{Km} 2$ area shown in Figure 1 . We adapted a new technique i.e. Arithmetic translation of pictorial models (ATOPM) to reduce unnecessary mathematical assumptions.

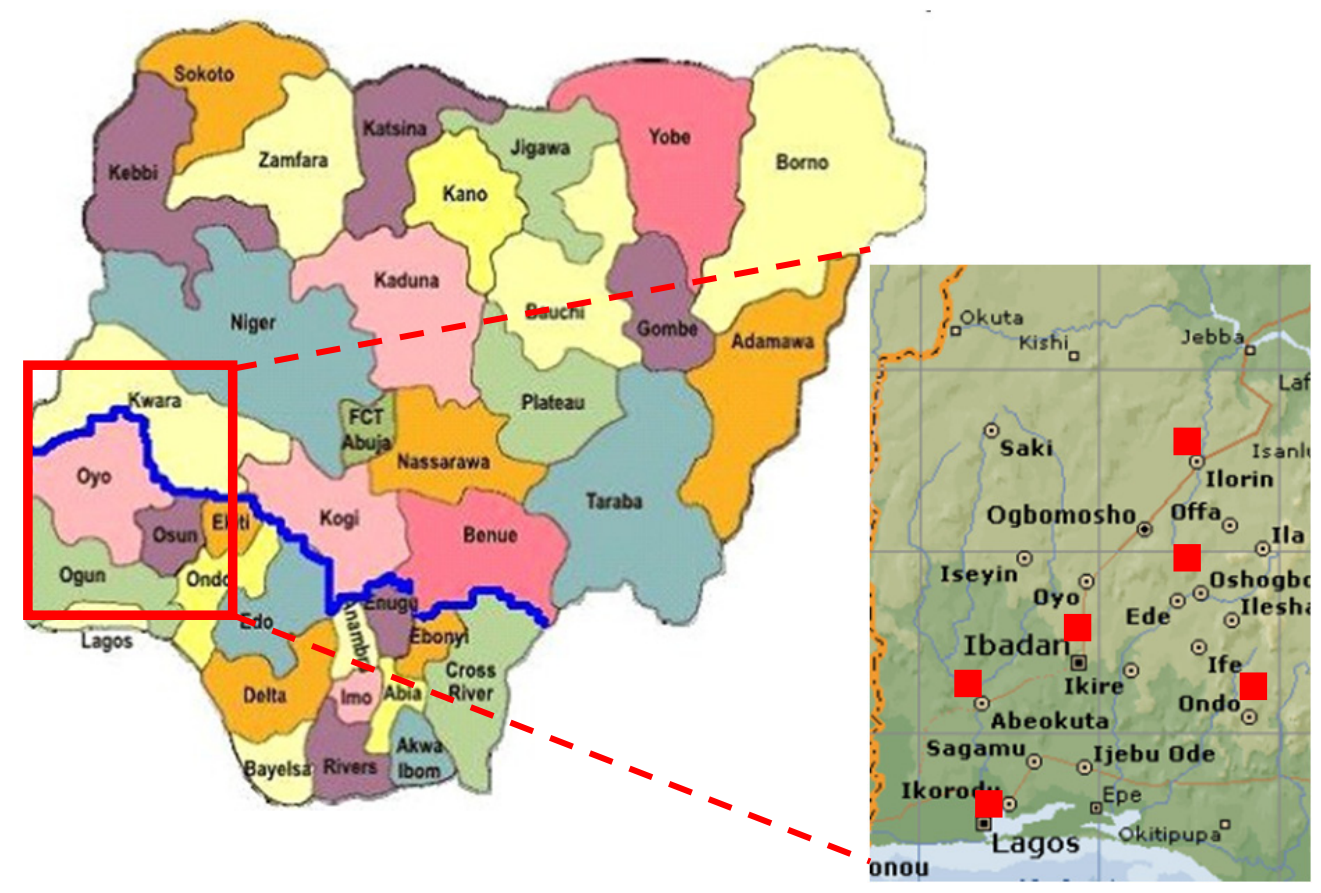

Figure 1. Location of study area in the enclave of Nigeria 


\section{Thirteen - Years Ground Data Assimilation}

The ground data set assimilation was carried-out using the MATLAB. Using the satellite imagery, it can be deduced that an increase in cloud cover leads to a decrease in AOT and vice-versa. This trend extends to other features of the cloud cover and its corresponding AOT. Hence, cloud cover is a valid parameter to estimate AOT in any area. Further, the ground data set shows that Ilorin has the highest cloud cover in the period of 2000-2012. The cloud cover for Abeokuta was not included in Figure (2) because it has a uniform cloud cover (i.e. 7) for fourteen years. The rainfall trend (Figure 3a-f) shows an inverse relationship i.e. an increased volume of rainfall (not frequency) leads to a decrease in the AOT output. An increased rainfall eliminates aerosol at the PBL.
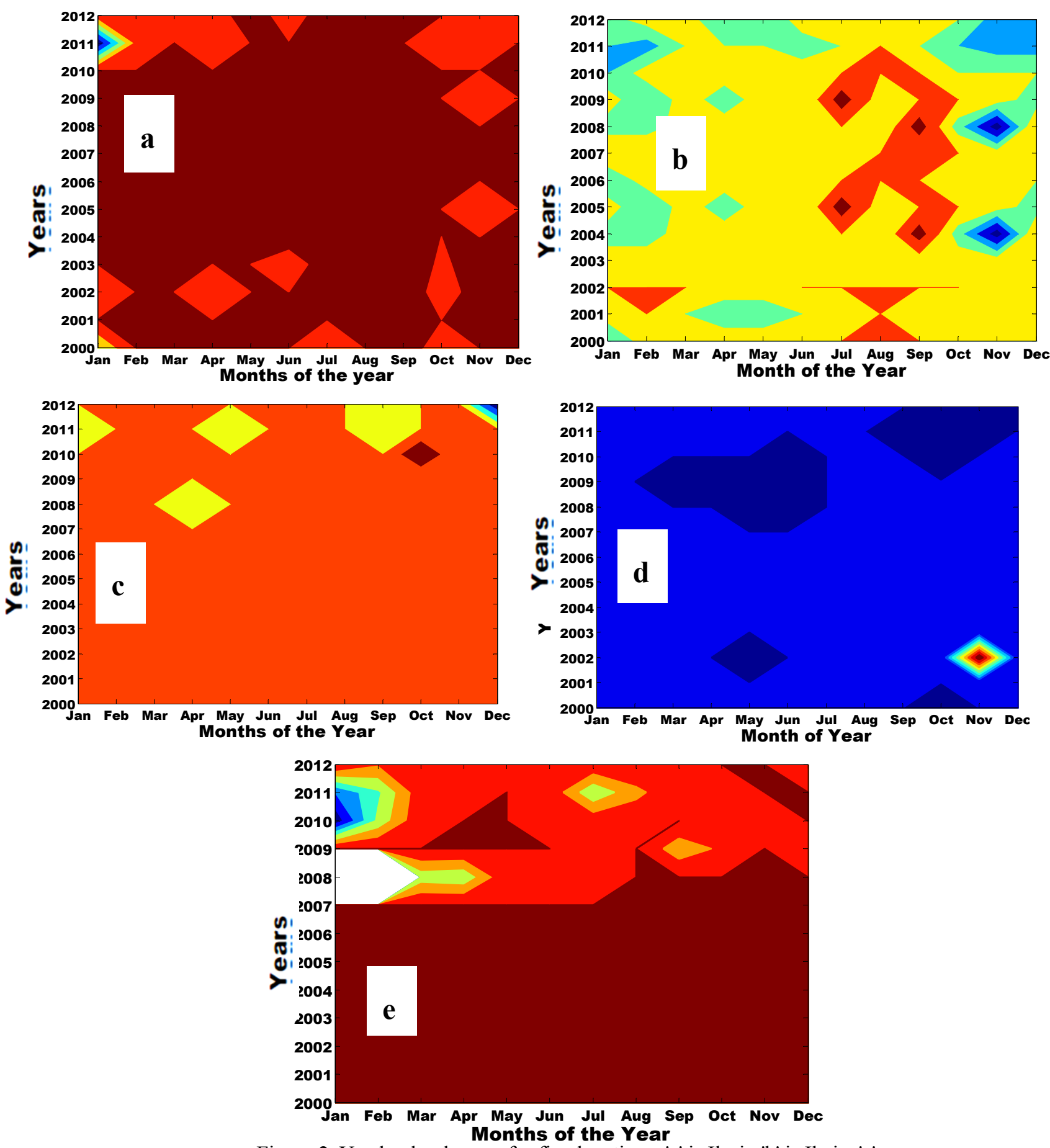

Figure 2. Yearly cloud cover for five locations. 'a' is Ilorin,' $b$ ' is Ikeja, 'c'

is Ibadan, ' $\mathrm{d}$ ' is Oshogbo, 'e' is Ondo 

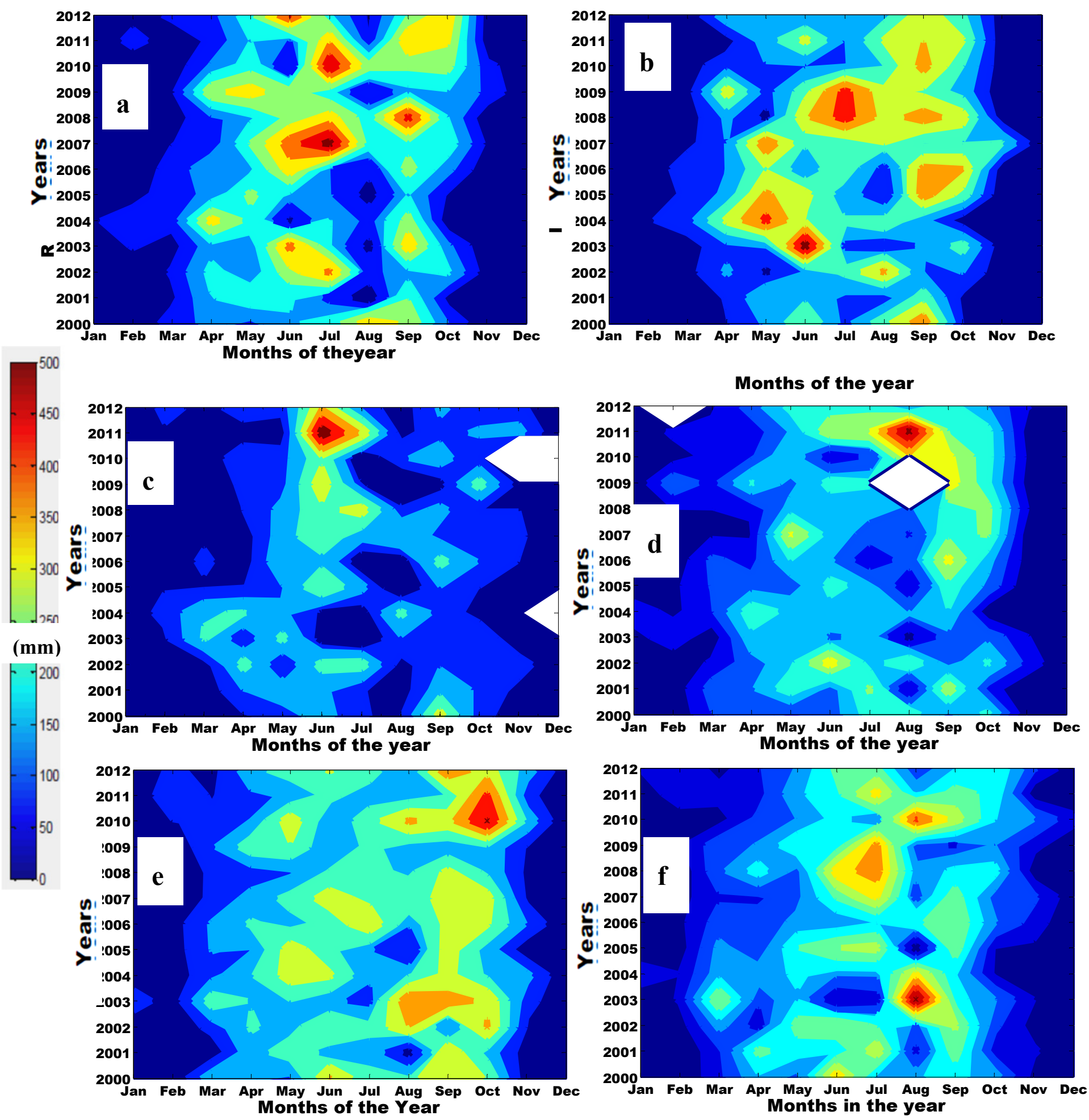

Figure 3. Yearly rainfall for six locations, 'a' is Abeokuta, 'b' is Ilorin,'c' is Ikeja , 'd' is Ibadan, 'e' is Oshogbo, ' $\mathrm{f}$ ' is Ondo

The relative humidity trend (Figure 4a-f) reveals a direct relationship between the relative humidity and AOT. 

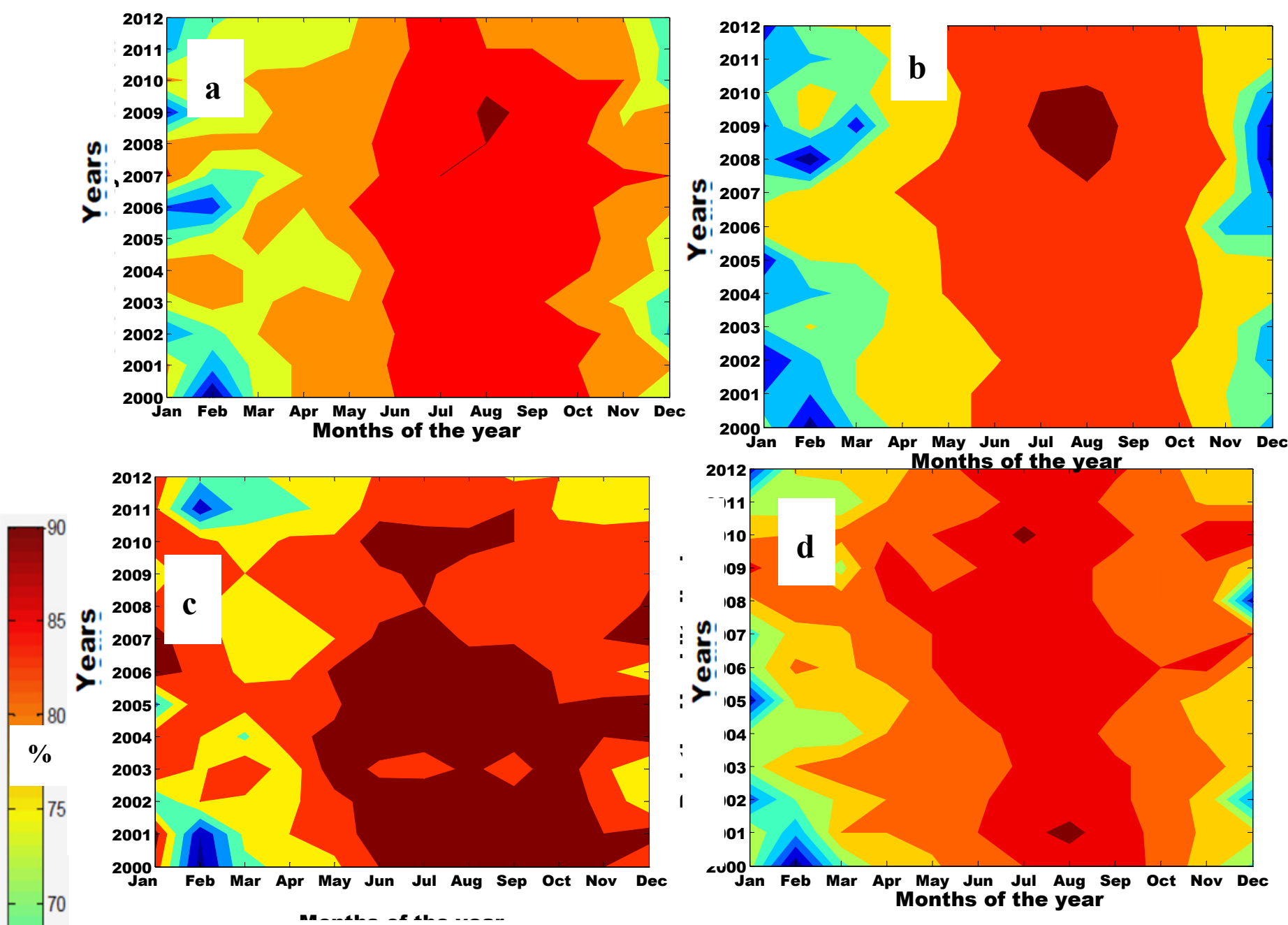

Months of the year
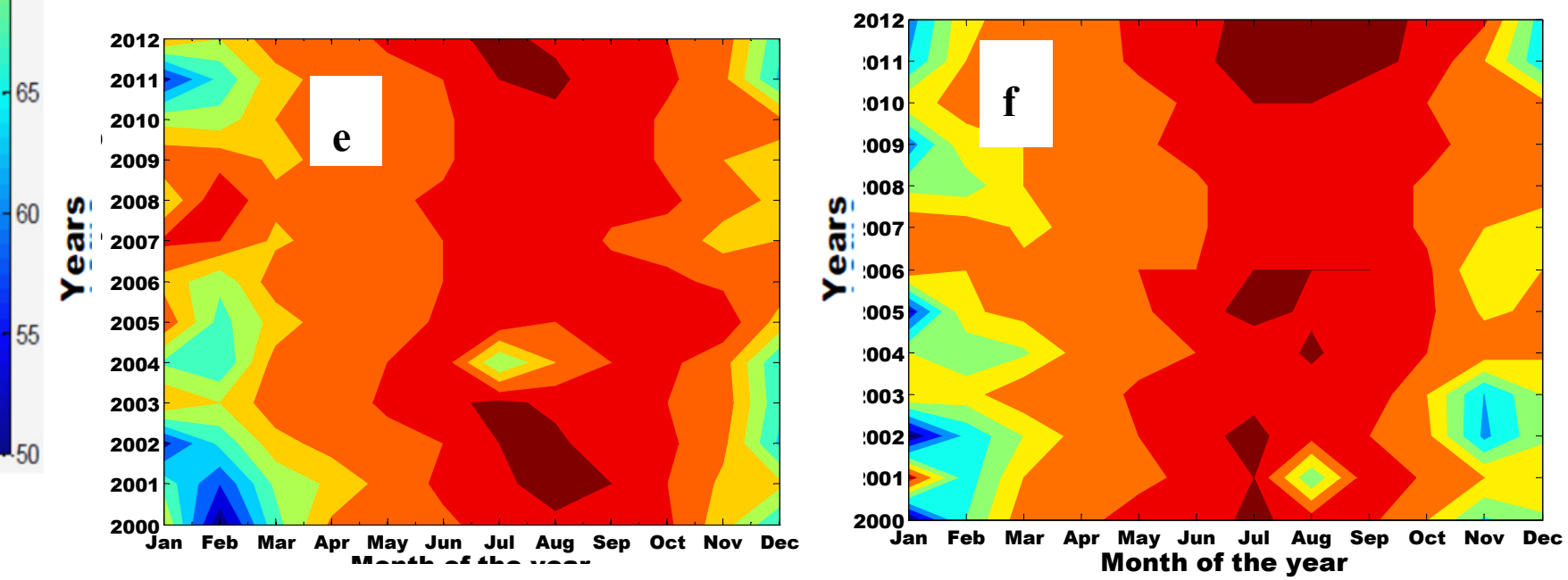

Figure 4. Yearly relative humidity for six locations. 'a' is Abeokuta, 'b' is Ilorin,'c' is Ikeja , 'd' is Ibadan, 'e' is Oshogbo, ' $\mathrm{f}$ ' is Ondo

The minimum temperature trend (see Figure 5a-f) showed an unstable relationship with the AOT. The stability of the relation between minimum temperature and AOT is sectionalized. 

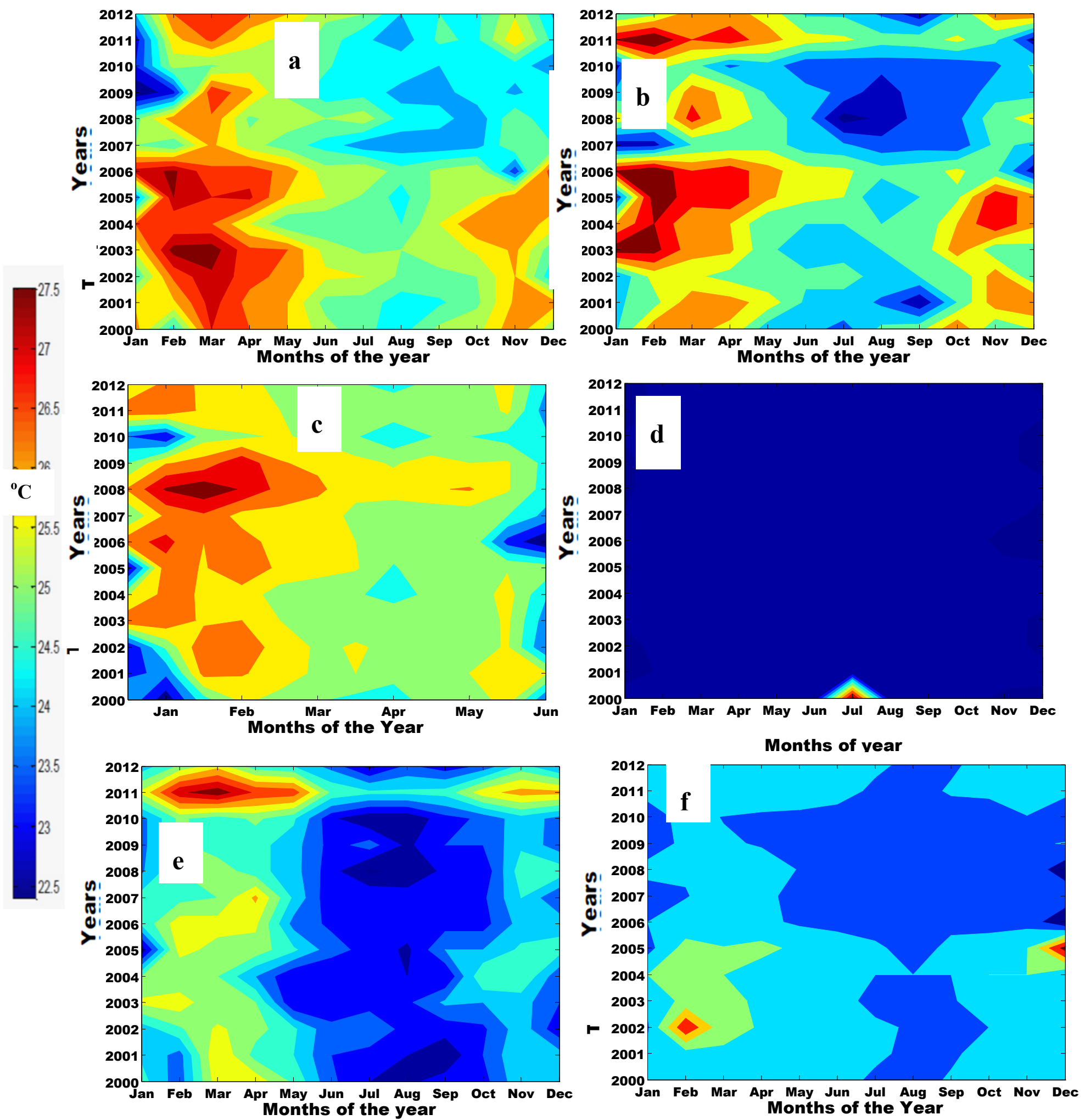

Figure 5. Yearly minimum temperature for six locations. 'a' is Abeokuta, 'b' is Ilorin,'c' is Ikeja , 'd' is Ibadan, 'e' is Oshogbo, ' $\mathrm{f}$ ' is Ondo

The minimum temperature is discarded because of its instability shown in Figure 5. Though in the past, Fitzgerald (1989) related the minimum temperature to AOT. However, with the results obtained from the six locations, no mathematical assumptions can practically capture all the known and unknown forces responsible 
for the thermal abnormally (Emetere, 2014). The best explanation for discarding minimum temperature is the realities of climate.

\section{Mathematical Formulations}

The success of the Kumierczyk-Michulec (1993) model was the mathematical translation of weather parameters in an equation given as

$$
\tau_{a}(\lambda)=a\left[\frac{E_{t o t}(\lambda)}{F_{s}(\lambda) \beta^{-1} \cos (\theta) T_{r}(\lambda)}-\frac{\left(1-T_{r}^{b}(\lambda)\right)}{c T_{r}(\lambda)}\right]^{\frac{d}{m}}
$$

Here, $\mathrm{a}=0.145, \mathrm{~b}=0.95, \mathrm{c}=2, \mathrm{~d}=0.945, E_{\text {tot }}(\lambda)$ is the total irradiance, $\lambda$ is the wavelength, $T_{r}(\lambda)$ is the transmittance functions for Rayleigh scattering, $F_{s}(\lambda)$ is the extra-terrestrial spectral irradiance, $\beta$ is the correction factor for the Earth-Sun distance. ' $m$ ' is single scattering albedo.

The data assimilation section enables the reconstruction equation (3) as

$$
\tau_{a}(\lambda)=a\left[\frac{E_{t o t}(\lambda)}{G_{S}(\lambda) \beta^{-1} \cos (\theta) T_{r}(\lambda)}-\frac{\left(1-T_{r}^{b}(\lambda)\right)}{c T_{r}(\lambda)}\right]
$$

Here $\mathrm{d} \approx \mathrm{m}, G_{s}(\lambda)$ is the extra-terrestrial index which can be determined by

$$
G_{S}(\lambda)=\left(\frac{G H}{J}\right)
$$

$\mathrm{G}$ is the cloud cover index, $\mathrm{H}$ is the relative humidity index, $\mathrm{J}$ is the rainfall index. The constants highlighted in equation (3) can be contested based of regional weather peculiarities and global climate change. Hence, the determination of constants should not be theoretical but practical. The spread of the events illustrated by the MATLAB simulation may be a vital clue towards generating the required constants. In this paper, we defined the constant by the events ratio during a specified period. For example, from Figure (6), we can deduce the constant from the individual index i.e. G, $\mathrm{H}$ and $\mathrm{J}$ shown in equations (6-8).
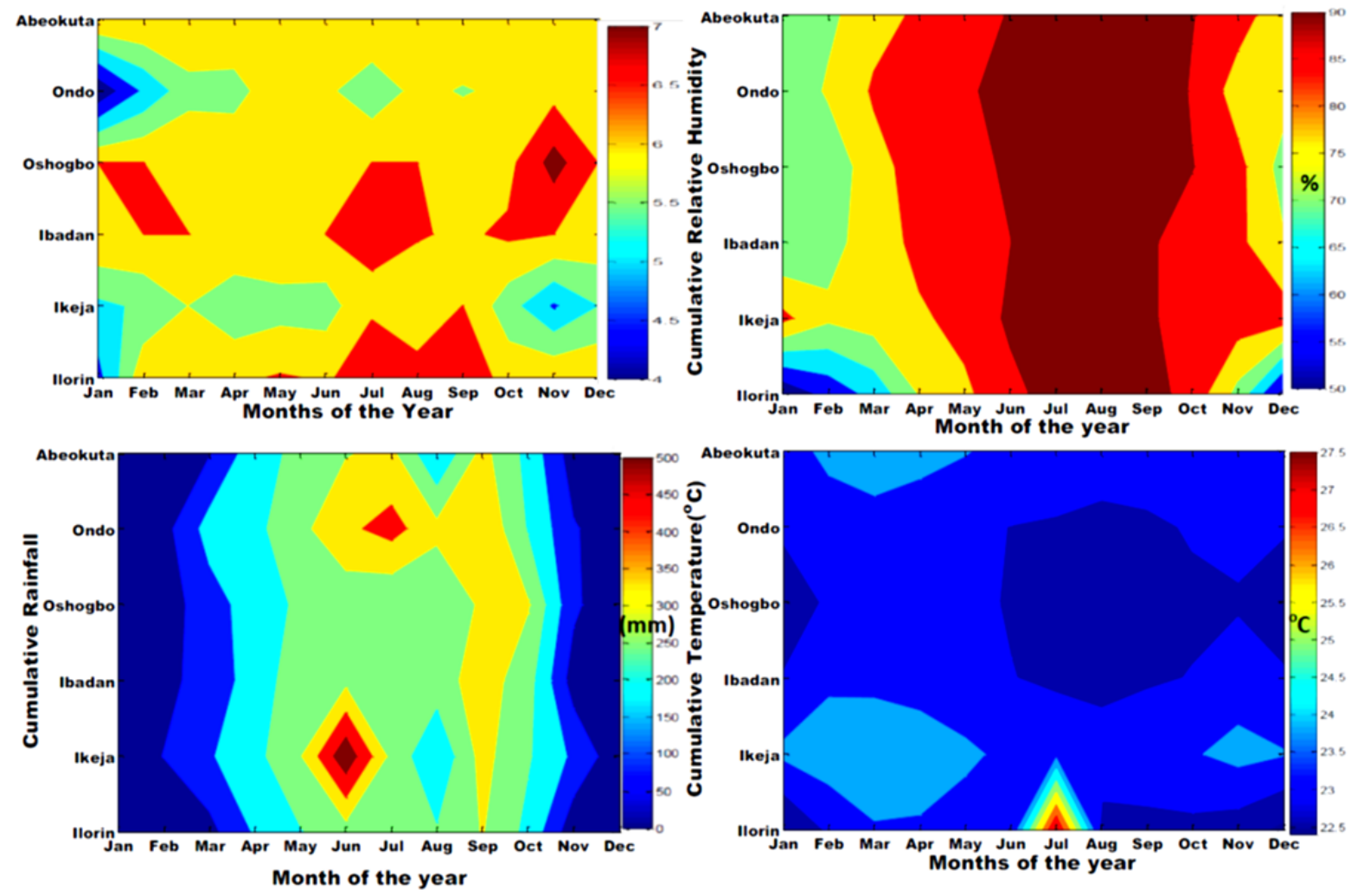

Figure 6: Monthly cumulative effects of parameters for fourteen years 
The cloud cover for each location is highlighted in equation (6), the relative humidity for each location is highlighted in equation (7) and the rainfall for each location is highlighted in equation (8). The vertical arrangement of the location in each equation is in order, Abeokuta, Ondo, Oshogbo, Ibadan, Ikeja and Ilorin.

$$
\begin{aligned}
& \left.\frac{2}{70} x_{1}+\frac{3}{70} x_{2}+\frac{5}{70} x_{3}+\frac{20}{70} x_{4}+\frac{40}{70} x_{5}\right) \\
& \frac{45}{70} x_{5}+\frac{23}{70} x_{6}+\frac{2}{70} x_{7} \\
& \frac{G}{\left(h-h_{0}\right)}=\quad \begin{array}{l}
70 \\
\frac{39}{70} x_{5}+\frac{31}{70} x_{6}
\end{array} \\
& \frac{14}{70} x_{3}+\frac{34}{70} x_{4}+\frac{22}{70} x_{5} \\
& \frac{3}{70} x_{3}+\frac{2}{70} x_{4}+\frac{44}{70} x_{5}+\frac{21}{70} x_{6} \\
& \frac{8}{70} y_{4}+\frac{14}{70} y_{5}+\frac{22}{70} y_{6}+\frac{26}{70} y_{7} \\
& \frac{6}{70} y_{4}+\frac{14}{70} y_{5}+\frac{20}{70} y_{6}+\frac{30}{70} y_{7} \\
& \frac{H}{\left(h-h_{0}\right)}=\quad \begin{array}{l}
\frac{12}{70} y_{4}+\frac{10}{70} y_{5}+\frac{21}{70} y_{6}+\frac{27}{70} y_{7} \\
\frac{9}{70} y_{4}+\frac{13}{70} y_{5}+\frac{27}{70} y_{6}+\frac{21}{70} y_{7}
\end{array} \\
& \frac{31}{70} y_{5}+\frac{23}{70} y_{6}+\frac{16}{70} y_{7} \\
& \frac{4}{70} y_{1}+\frac{6}{70} y_{2}+\frac{6}{70} y_{3}+\frac{7}{70} y_{4}+\frac{13}{70} y_{5}+\frac{13}{70} y_{6}+\frac{21}{70} y_{7} \\
& \frac{21}{70} z_{1}+\frac{7}{70} z_{2}+\frac{13}{70} z_{3}+\frac{17}{70} z_{4}+\frac{12}{70} z_{5} \\
& \frac{13}{70} z_{1}+\frac{9}{70} z_{2}+\frac{13}{70} z_{3}+\frac{9}{70} z_{4}+\frac{20}{70} z_{5}+\frac{6}{70} z_{6} \\
& \frac{J}{\left(h-h_{0}\right)}=\begin{array}{l}
\frac{15}{70} z_{1}+\frac{10}{70} z_{2}+\frac{8}{70} z_{3}+\frac{28}{70} z_{4}+\frac{9}{70} z_{5} \\
\frac{15}{70} z_{1}+\frac{10}{70} z_{2}+\frac{9}{70} z_{3}+\frac{29}{70} z_{4}+\frac{7}{70} z_{5}
\end{array} \\
& \frac{10}{70} z_{1}+\frac{14}{70} z_{2}+\frac{19}{70} z_{3}+\frac{16}{70} z_{4}+\frac{5}{70} z_{5}+\frac{4}{70} z_{6}+\frac{3}{70} z_{7} \\
& \frac{22}{70} z_{1}+\frac{6}{70} z_{2}+\frac{11}{70} z_{3}+\frac{29}{70} z_{4}+\frac{2}{70} z_{5}
\end{aligned}
$$

$h-h_{0}$ height difference from ground. $\mathrm{x} 1-\mathrm{x} 7, \mathrm{y} 1-\mathrm{y} 7$ and $\mathrm{z} 1-\mathrm{z} 7$ represents the distribution sizes obtained from the diagram for each indices. The generalized constants obtained from the research site can be estimated via the summation of all the events in each index as shown in equation (9).

$$
\left.\begin{array}{l}
\frac{G}{\left(h-h_{0}\right)}=\frac{2}{70} x_{1}+\frac{3}{70} x_{2}+\frac{22}{70} x_{3}+\frac{56}{70} x_{4}+\frac{220}{70} x_{5}+\frac{52}{70} x_{6}+\frac{2}{70} x_{7} \\
\frac{H}{\left(h-h_{0}\right)}=\frac{4}{70} y_{1}+\frac{6}{70} y_{2}+\frac{6}{70} y_{3}+\frac{42}{70} y_{4}+\frac{64}{70} y_{5}+\frac{103}{70} y_{6}+\frac{155}{70} y_{7} \\
\frac{J}{\left(h-h_{0}\right)}=\frac{96}{70} z_{1}+\frac{61}{70} z_{2}+\frac{73}{70} z_{3}+\frac{117}{70} z_{4}+\frac{55}{70} z_{5}+\frac{10}{70} z_{6}+\frac{5}{70} z_{7}
\end{array}\right\}
$$

From the proofs on wavelength dependence on aerosol optical depth (Angstroms,1929; Eck et al., 1999), we assume a formular whose relation to the wavelength is divergent (if directly related) $x_{n}=\lambda \sin (n \theta), y_{n}=$ $\frac{\lambda}{n} \sin (n \theta)$, and convergent (if inversely related) $z_{n}=\frac{\lambda^{2}}{n} \cos (n \theta)$. The proof on the effect of angular shift $(n \theta)$ on results in equation (4) is affirmed in the individual weather parameter shown in Figure (7-9). $n$ is the number of particles $\left(1 / \mathrm{cm}^{3}\right)$. 


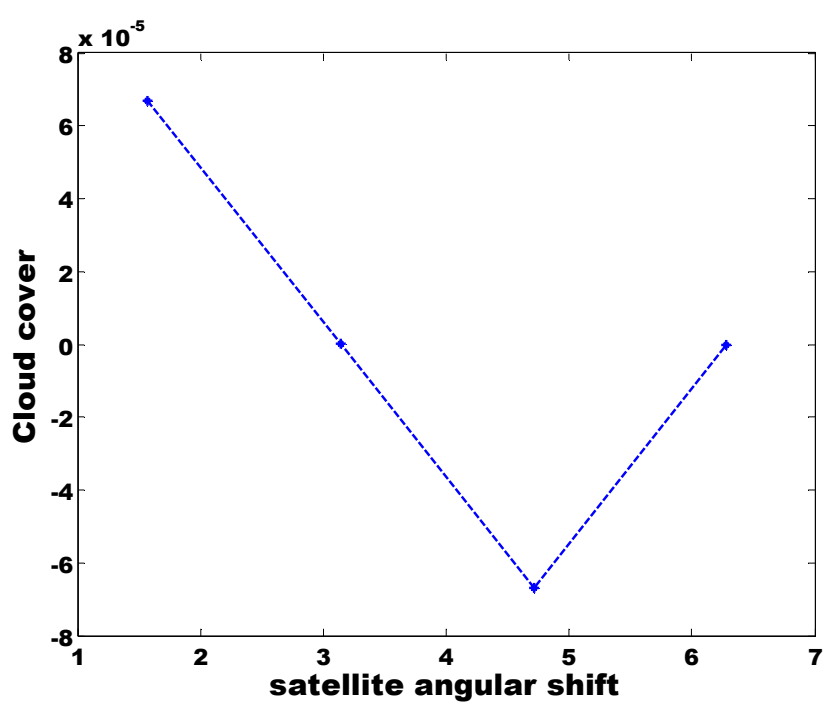

Figure 7. Satellite angular shift effect on the cloud cover

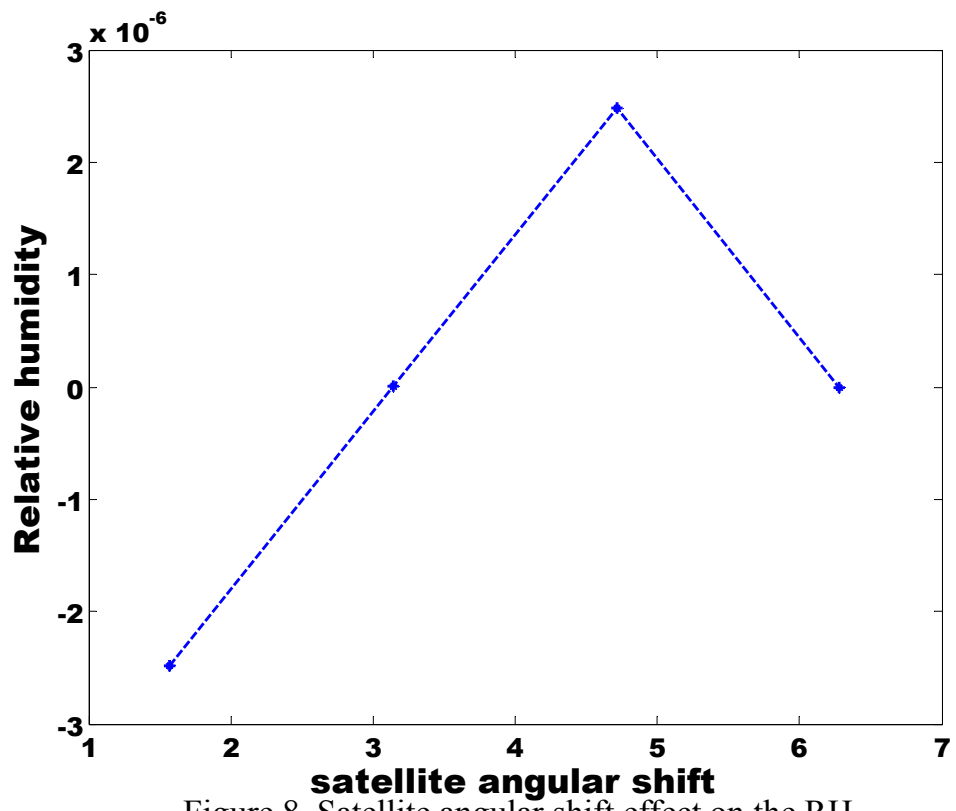

Figure 8. Satellite angular shift effect on the RH

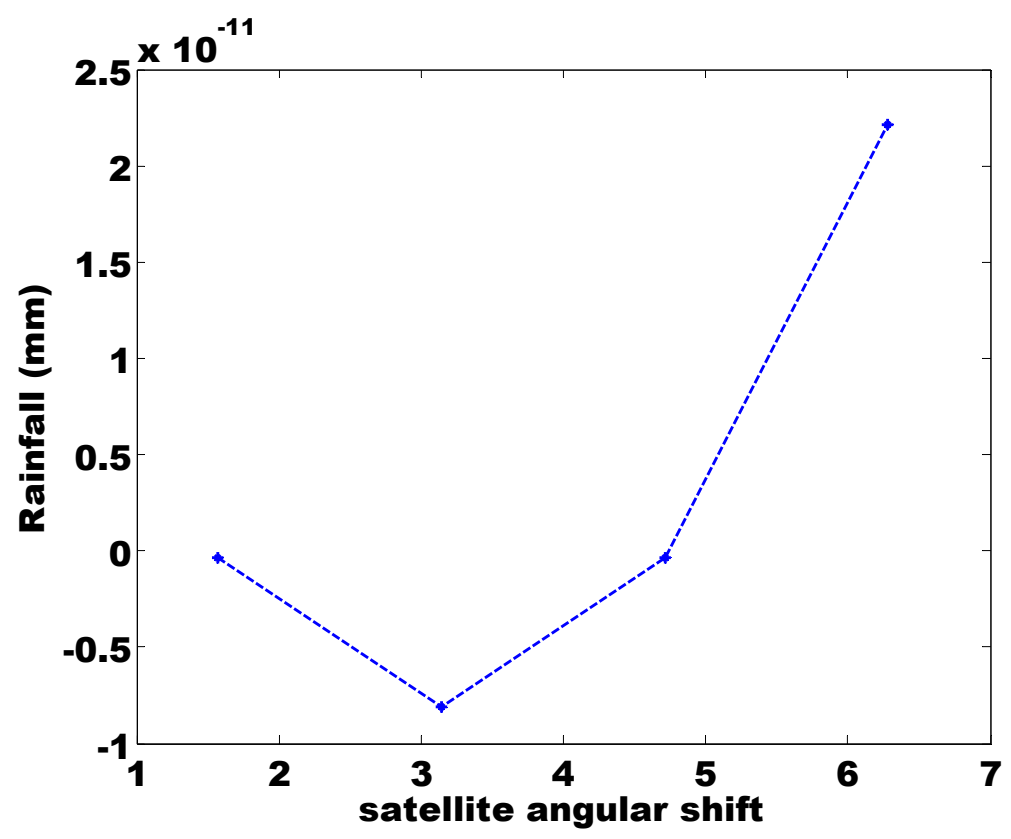

Figure 9. Satellite angular shift effect on the Rainfall

Recall that the objective of the paper is to determine the rough estimation of the aersol distribution sizes. In Figures 7-9, a microscopic analysis of each parameter was investigated. We observe the progression of each parameter from the negative to the positive value. Cloud cover is negatively linear while rainfall is positive linear on their positive ordinate. Relative humidity has both positive and negative linearity at positive ordinate.

The weather parameters were considered i.e. cloud cover index at $20 \mathrm{~m}$ above the PBL, relative humidity index at $20 \mathrm{~m}$ above the PBL, Rainfall index at $20 \mathrm{~m}$ above the PBL and extra-terrestrial index are illustrated below in tables 1 .The index was obtained by converting equation (9) into polynomial. For example the index for Abeokuta is shown in Figure (10).

As shown below, the maximum indexes are inscribed in Figure (10). The positive parabola relationship between 
the indexes and its weather parameter (e.g. cloud cover index and cloud cover) shows that they are directly proportional to one another. Also, the depth of relationship depends on the steepness of the parabola and the magnitude of the index. The 3D Figure (10) shows the effects of control constants to maintain the AOT below 1. The control constants are applied in the simulation to restrict the AOT to 0 and 0.8 . The control constant for rainfall index is denoted as 'a', the control constant for relative humidity and cloud cover is denoted as ' $b$ ' and ' $c$ ' respectively. ' $\mathrm{b}$ ' and ' $\mathrm{c}$ ' were kept constant throughout the experiment and 'a' varied. The result of other locations is summarized in table 1. Ondo has the highest relative humidity index (RHI), Oshogbo has the highest cloud cover index(CCI), Ondo has the highest rainfall index (RI) and Ilorin has the highest controlling constant ' $a$ '.
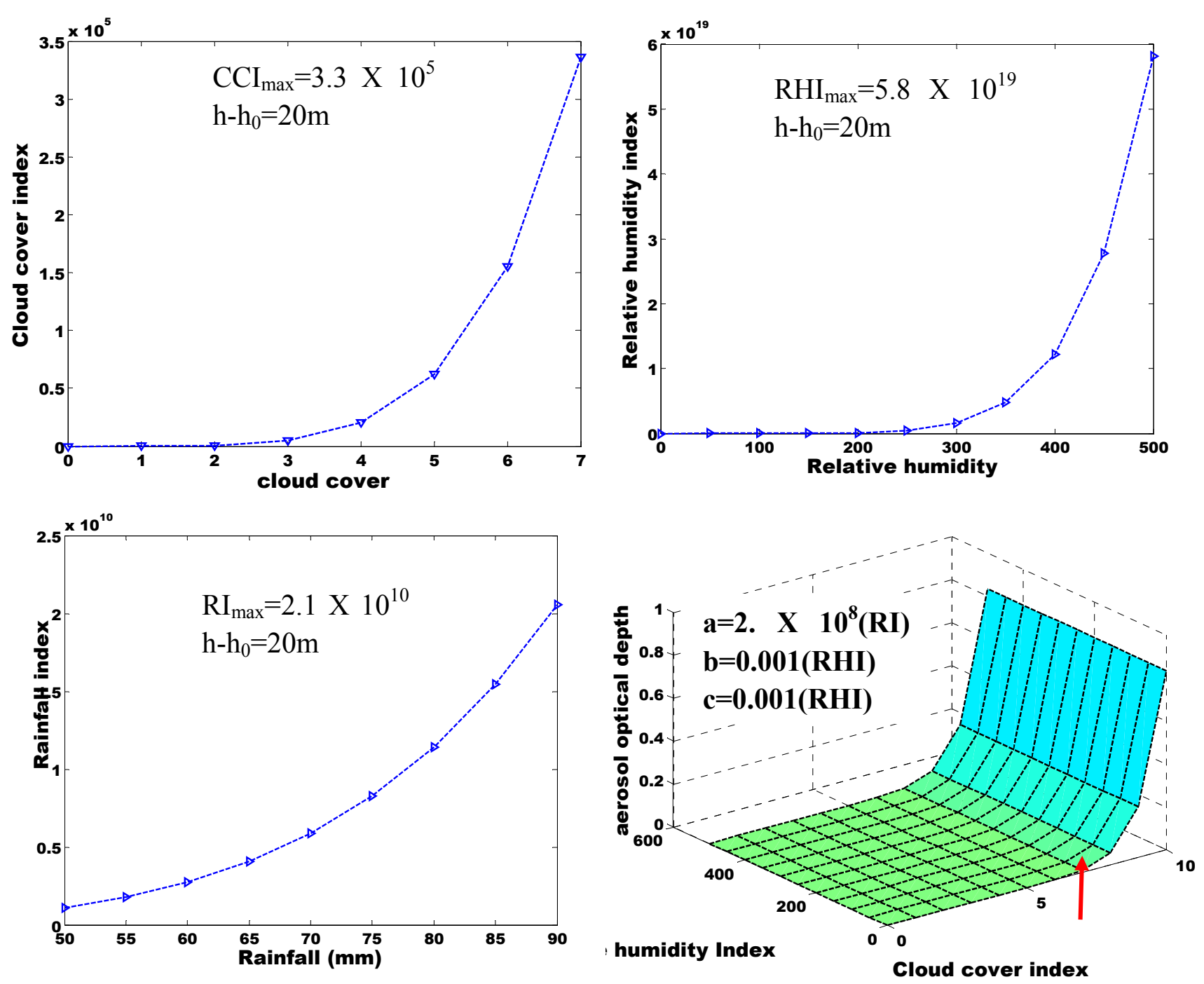

Figure 10. Polynomial analysis of Index-Abeokuta 
Table 1. Index table of parameters

\begin{tabular}{lllll}
\hline Location & CCI & RHI & RI & a \\
\hline Abeokuta & $3.3 \times 10^{5}$ & $5.8 \times 10^{19}$ & $2.1 \times 10^{10}$ & $2.0 \times 10^{8}$ \\
Ondo & $1.2 \times 10^{6}$ & $\mathbf{6 . 7} \times \mathbf{1 0}^{\mathbf{1 9}}$ & $\mathbf{1 . 7} \times \mathbf{1 0}$ & $3.0 \times 10^{6}$ \\
Oshogbo & $\mathbf{1 . 3 6} \times \mathbf{1 0}^{\mathbf{7}}$ & $6.1 \times 10^{19}$ & $1.38 \times 10^{7}$ & $2.0 \times 10^{9}$ \\
Ibadan & $1.0 \times 10^{7}$ & $4.7 \times 10^{19}$ & $2.1 \times 10^{10}$ & $1.5 \times 10^{9}$ \\
Ikeja & $7.3 \times 10^{5}$ & $3.6 \times 10^{19}$ & $7.3 \times 10^{5}$ & $2.0 \times 10^{4}$ \\
Ilorin & $7.1 \times 10^{6}$ & $4.7 \times 10^{19}$ & $7.3 \times 10^{6}$ & $\mathbf{3 . 0} \times \mathbf{1 0}$ \\
\hline
\end{tabular}

The index reveals the cumulative effect in numerical value. High index shows a region of lower activity of its parameter and vice-versa. For example, in descending order, the CCI-according to location is listed as follows Osun, Ibadan, Ilorin, Ondo, Ikeja and Abeokuta. This means that Abeokuta is more prone to cloud cover than osun.

\section{Application of the Model to Practical Problems}

Equation (4) was tested by generating series of AOT values shown in table 2. The AOT was generated via a changing angular range.

Table 2. AOT predictions over the area

\begin{tabular}{cccccccccc}
\hline Angle & \multicolumn{7}{c}{ Likely data sets of Aerosol Optical Thickness (AOT) for 10m-1Km vertical profile } \\
\hline $\mathrm{Pi} / 2$ & 0.0286 & 0.0571 & 0.0857 & 0.1142 & 0.1428 & 0.1713 & 0.1999 & 0.2284 & 0.257 \\
$2 \mathrm{Pi} / 3$ & 0.5425 & 0.571 & 0.5996 & 0.6281 & 0.6567 & 0.6852 & 0.7138 & 0.7423 & 0.779 \\
$\mathrm{pi}$ & 1.0564 & 1.085 & 1.1135 & 1.1421 & 1.1706 & 1.1992 & 1.2277 & 1.2563 & 1.2848 \\
$3 \mathrm{pi} / 2$ & 1.5703 & 1.5989 & 1.6275 & 1.656 & 1.6846 & 1.7131 & 1.7417 & 1.7702 & 1.7988 \\
$2 \mathrm{pi}$ & 2.0843 & 2.1128 & 2.1414 & 2.1699 & 2.1985 & 2.227 & 2.2556 & 2.2841 & 2.3127 \\
Angle & \multicolumn{7}{c}{ Likely data sets of Aerosol Optical Thickness (AOT) for 10m-1Km vertical profile } \\
$\mathrm{Pi} / 2$ & 0.2855 & 0.3141 & 0.3426 & 0.3712 & 0.3997 & 0.4283 & 0.4568 & 0.4854 & 0.5139 \\
$2 \mathrm{Pi} / 3$ & 0.7994 & 0.828 & 0.8566 & 0.8851 & 0.9137 & 0.9422 & 0.978 & 0.9993 & 1.0279 \\
$\mathrm{pi}$ & 1.3134 & 1.3419 & 1.3705 & 1.399 & 1.4276 & 1.4561 & 1.4847 & 1.5132 & 1.5418 \\
$3 \mathrm{pi} / 2$ & 1.8273 & 1.8559 & 1.8844 & 1.913 & 1.9415 & 1.9701 & 1.9986 & 2.0272 & 2.0557 \\
$2 \mathrm{pi}$ & 2.3412 & 2.3698 & 2.3983 & 2.4269 & 2.4555 & 2.484 & 2.5126 & 2.5411 & 2.5697 \\
\hline \multicolumn{7}{c}{}
\end{tabular}

The sensitivity of the model was tested (in table 3) to show a clear distinction between seemingly AOT locations. The positioning of the indexes and the cumulative performance is shown below.

Table 3. Forecasting via index positioning

\begin{tabular}{cccccccccc}
\hline Location & CCI & $\mathbf{P}$ & RHI & $\mathbf{P}$ & RI & $\mathbf{P}$ & $\mathrm{a}$ & $\mathbf{P}$ & $\mathbf{R}$ \\
\hline Abeokuta & $3.3 \times 10^{5}$ & $\mathbf{6}$ & $5.8 \times 10^{19}$ & $\mathbf{3}$ & $2.1 \times 10^{10}$ & $\mathbf{3}$ & $2.0 \times 10^{8}$ & $\mathbf{4}$ & $\mathbf{2 1 6}$ \\
Ondo & $1.2 \times 10^{6}$ & $\mathbf{4}$ & $6.7 \times 10^{19}$ & $\mathbf{1}$ & $1.7 \times 10^{12}$ & $\mathbf{1}$ & $3.0 \times 10^{6}$ & $\mathbf{5}$ & $\mathbf{2 0}$ \\
Oshogbo & $1.36 \times 10^{7}$ & $\mathbf{1}$ & $6.1 \times 10^{19}$ & $\mathbf{2}$ & $1.38 \times 10^{7}$ & $\mathbf{5}$ & $2.0 \times 10^{9}$ & $\mathbf{2}$ & $\mathbf{2 0}$ \\
Ibadan & $1.0 \times 10^{7}$ & $\mathbf{2}$ & $4.7 \times 10^{19}$ & $\mathbf{4}$ & $2.1 \times 10^{10}$ & $\mathbf{3}$ & $1.5 \times 10^{9}$ & $\mathbf{3}$ & $\mathbf{7 2}$ \\
Ikeja & $7.3 \times 10^{5}$ & $\mathbf{5}$ & $3.6 \times 10^{19}$ & $\mathbf{6}$ & $7.3 \times 10^{5}$ & $\mathbf{6}$ & $2.0 \times 10^{4}$ & $\mathbf{6}$ & $\mathbf{1 0 8 0}$ \\
Ilorin & $7.1 \times 10^{6}$ & $\mathbf{3}$ & $4.7 \times 10^{19}$ & $\mathbf{4}$ & $7.3 \times 10^{6}$ & $\mathbf{2}$ & $3.0 \times 10^{9}$ & $\mathbf{1}$ & $\mathbf{2 4}$ \\
\hline
\end{tabular}

The multiplication of the positions is expressed in the column-marked 'R'. We propose that region of exceeding 
high value of 'R' (i.e. $\mathrm{R}>100$ ) symbolizes region prone to errors. Therefore, Lagos and Abeokuta are highly prone to errors. Ondo and Oshogbo lies almost on the same horizon. They possess low 'R' (i.e. $R<100$ ) showing that the inclusion of either theoretical or practical constant would be almost accurate. Ilorin and Ibadan are almost in the class of Ondo and Oshogbo. Hence, when compared to previous models (De et al., 2003; Falaiye et al., 2013), the sensitivity of this model is about $0.1 \%$ higher.

\section{Conclusion}

The aerosol optical thicknesses within the research site shows dependence on the wavelength and satellite angular shift. The validation of the mathematical connection between AOT and weather parameters has been established. The type of relationship between AOT and weather parameters can be direct or inverse. The assimilation of the fourteen years ground data set shows that some parameters like minimum temperature have been overtaken by the global climatic change. However, the sensitivity of this model was comparatively analyzed to be $0.1 \%$. Hence, the south-west Nigeria aerosol activity may be the highest compared to northern Nigerian. Therefore more attention should placed on Lagos and Ogun state as its aerosol content may increase beyond control.

\section{Acknowledgement}

The authors gratefully acknowledge the NASA and Nigeria Meteorological Center for allowing the use of the satellite and ground data set respectively. The authors declare that they have no competing interests.

\section{References}

Angstrom, A. (1929). On the atmospheric transmission of sun radiation on dust in the air. Geogr Ann., 12, 130-159.

Bird, R. E. (1984). A simple, solar spectral model for direct-normal and diffuse horizontal irradiance. Solar Energy, 32(4), 461-471,

Böckmann, C. (2001). Hybrid Regularization Method for the Ill-posed Inversion of Multiwavelength Lidar Data in the Retrieval of Aerosol Size Distributions. Applied Optics, 40(9), 1329-1342.

De Tomasi, F., Blanco, A., \& Perrone, M. R. (2003). Raman lidar monitoring of extinction and backscattering of African dust layers and dust characterization, Appl. Optics, 42(9), 1699-1709.

Eck, T. F., Holben, B. N., Reid, J. S., Dobovik, O., Smirnov, A., O'Neill, N. T., Slutsker, I., \& Kinne, S. (1999). wavelength dependence of the optical depth of biomass burning, urban and desert dust aerosols. Journal of Geophysical Research, 104(D24), 31333-31349.

Emetere, Moses. E. (2014). Forecasting Hydrological Disaster Using Environmental Thermographic Modeling. Advances in Meteorology 2014,783718

Emetere, Moses, E., \& Akinyemi, M. L. (2013). Modeling Of Generic Air Pollution Dispersion Analysis From Cement Factory. Analele Universitatii din Oradea-Seria Geografie 231123-628, 181-189.

Emetere, Moses E. (2013). Modeling Of Particulate Radionuclide Dispersion And Deposition From A Cement Factory. Annals of Environmental Science, 7(6), 71-77.

Emetere, Moses E. (2014). Theoretical Forecast of the Health Implications of Citing Nuclear Power Plant in Nigeria. Journal of Nuclear and Particle Physics, 4(3), 87-93.

Falaiye, O. A., Yakubu, A. T., Aweda, F. O., \& Abimbola, O. J. (2013). Mineralogical Characteristics of Harmattan Dust In Ilorin, Sub-Sahara Africa. Ife Journal of Science, 15(1), 175-181.

Fitzgerald, J. W. (1989). Model of the aerosol extinction profile in a well-mixed marine boundary layer. Appl. Opt., 28(15), 3534-3538.

Hoff, R., \& Christopher, S. A. (2009). Remote sensing of particulate pollution from space: have we reached the promised land? J. Air Waste Manage., 59, 645-675.

Hollingsworth, A., Engelen, R. J., Textor, C., Benedetti, A., Boucher, O., Chevallier, F., ... Consortium, G. (2008). Toward a monitoring and forecasting system for atmospheric composition: The gems project. $B$. Am. Meteorol. Soc., 89, 1147-1164.

Kumierczyk-Michulec, Jolanta. (1993). The aerosol optical thickness of the atmosphere over the Norwegian Sea obtained from different experimental data. Oceanologia, 34, 27-37.

NASA. (2009). http://www.nasa.gov/audience/foreducators/9-12/features/giovanni-an-easier-way.html 
Tanré, D., Devaux, C., Herman, M., \& Santer, R. (1988). Radiative Properties of Desert Aerosols by Optical Ground-Based Measurements at Solar Wavelengths. Journal Of Geophysical Research, 93(11), 14, 223-14, 231.

von Hoyningen-Huene, W., Dinter, T., Kokhanovsky, A. A., Burrows, J. P., \& Diouri, M. (2008). Radiative properties of desert dust for satellite remote sensing of aerosol optical thickness. Tellus 61B, http://dx.doi.org/10.1111/j.1600-0889.2008.00405.x.

Wang, J., \& Christopher, S. A. (2003). Intercomparison between satellite derived aerosol optical thickness and PM2.5 mass: Implications for air quality studies. Geophys. Res. Lett., 30(21), 2095. http://dx.doi.org/10.1029/2003GL018174,

Wang, Y. F., Fan, S., Feng, X., Yan, G. J., \& Guan, Y. N. (2006). Regularized inversion method for retrieval of aerosol particle size distribution function in W1,2 space. Applied Optics, 45(28), 7456-7467.

Zhang, J. L., Reid, J. S., Westphal, D. L., Baker, N., \& Hyer, E. J. (2008). A system for operational aerosol optical depth data assimilation over global oceans. J. Geophys. Res., 113, D10208, http://dx.doi.org/10.1029/2007JD009065

\section{Copyrights}

Copyright for this article is retained by the author(s), with first publication rights granted to the journal.

This is an open-access article distributed under the terms and conditions of the Creative Commons Attribution license (http://creativecommons.org/licenses/by/3.0/). 